Portland State University

PDXScholar

Spring 6-4-2019

\title{
Evaluating the Utility of Theories of Social Integration in Understanding Areal Suicide Rates in the United States
}

Nathan Finch Parsons

Portland State University

Follow this and additional works at: https://pdxscholar.library.pdx.edu/open_access_etds

Part of the Sociology Commons

Let us know how access to this document benefits you.

Recommended Citation

Parsons, Nathan Finch, "Evaluating the Utility of Theories of Social Integration in Understanding Areal Suicide Rates in the United States" (2019). Dissertations and Theses. Paper 5042.

https://doi.org/10.15760/etd.6918

This Thesis is brought to you for free and open access. It has been accepted for inclusion in Dissertations and Theses by an authorized administrator of PDXScholar. Please contact us if we can make this document more accessible: pdxscholar@pdx.edu. 
Evaluating the Utility of Theories of Social Integration in Understanding Areal Suicide

Rates in the United States.

by

Nathan Finch Parsons

A thesis submitted in partial fulfillment of the requirements for the degree of

\author{
Master of Science \\ In \\ Sociology
}

Thesis Committee:

Hyeyoung Woo, Chair

Julius McGee

Lindsey Wilkinson

Portland State University

2019 
(C)2019

Nathan Finch Parsons 


\begin{abstract}
Despite over a century's worth of study, areal variations in suicide rate remain largely unexplained. In order to better understand these regional differences, this analysis aggregates county-level National Center for Health Statistics Multiple Cause of Death data with data from the US Census, the Association of Statisticians of American Religious Bodies, and the Penn State Northeast Regional Center for Rural Development to test the three leading conceptualizations of social integration (i.e. demographic, compositional, ecological) against US suicide rates. Results of negative binomial regression models indicate that an ecological measure, social capital, is substantially associated with suicide rate, while demographic and compositional measures do not appear to be significantly associated with suicide rate, robust of controls, speaking to the role of social ties in preventing suicide. These findings highlight both the changing nature of social integration and the role that this plays in suicide prevention.
\end{abstract}


Dedication

To Amanda, without whose patience, encouragement, and support this project would never have been possible. 


\section{Acknowledgments}

I would like to acknowledge the advice, support, and encouragement of my advisor and chair, Dr. Hyeyoung Woo, and the seemingly infinite patience of my committee in the face of delays, false starts, and one government shut-down. Thank you all. 
Table of Contents

Abstract 
List of Tables

Table 1. Sociodemographic Characteristics of Suicide Mortality Data from National

Center for Health Statistics 19

Table 2. County Level Descriptive Statistics (Source: National Center for Health Statistics, US Census, ARDA, NERCRD).................................................... 28

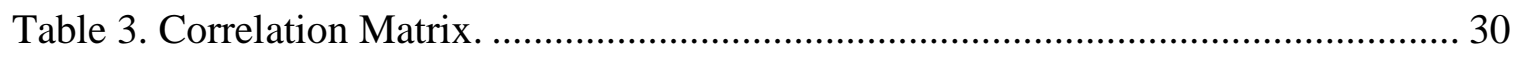

Table 4. Negative Binomial Regression of County-level Age-adjusted Suicide Rates on Demographic and Control Variables.

Table 5. Negative Binomial Regression of County-level Age-adjusted Suicide Rates on Compositional and Control Variables.

Table 6. Negative Binomial Regression of County-level Age-adjusted Suicide Rates on Ecological and Control Variables. 38

Table 7. Negative Binomial Regression of County-level Age-adjusted Suicide Rates on Predictor and Control Variables. 
List of Figures

Figure 1. Age-adjusted suicide rate by US Census Region, 1999-2017. (source: CDC WONDER) ........................................................................................... 4

Figure 2. Age-adjusted suicide rate by US Census Division, 1999-2017. (source: CDC WONDER) ........................................................................................ 5

Figure 3. States with the 10 highest suicide rates by US Census Division, 1999-2017.

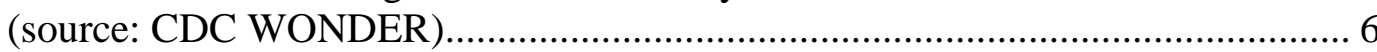

Figure 4. Illustration of the 3ST theory of suicide. (source: Klonsky and May 2015) ..... 10 
Introduction

The nature of mortality in the United States has shifted significantly over the last century. Advances in biology, chemistry, public health, and epidemiology have generated new ways of understanding the movement of pathogens through populations; new understandings which have in turn lead to novel methods of intervention and new cures for some of the deadliest diseases on the planet. Moreover, recent insights into our genetic composition, pharmacological breakthroughs, holistic approaches to lifestyle, diet, and environment, and new tools such as clustered regularly interspaced short palindromic repeats (CRISPR) and magnetic resonance imaging (MRI) have extended the power of public health professionals to begin to mitigate the toll of chronic and contextual disease conditions such as obesity, diabetes, and heart disease, allowing individuals to live longer, fuller, healthier lives. This shift is reflected in the list of leading causes of death affecting Americans: communicable diseases give way to chronic conditions, chronic conditions become less fatal, life spans increase. Overall mortality from all causes declined $54 \%$ between 1900 and 2010, and the disease burden of pneumonia, tuberculosis, infection, diphtheria, measles, mumps, and rubella is but a shadow of its former self (Tippett 2014). Unfortunately, not all causes of mortality are on the decline. One of the leading causes of mortality among Americans is neither communicable nor chronic, is little understood by physicians and researchers alike, and increased nearly thirty percent among all persons between the ages of 10 and 74 between 1999 and 2014 without regard for race, sex, income, or faith (Curtin, Warner, and Hedegaard 2016). 
Suicide is the second leading cause of deaths among those between the ages of 10 and 24 (Heron 2018), is in the top four leading causes of death among white males between the ages of 10 and 54 (Office of Minority Health and Health Equity 2018), and affects female military veterans at a rate 2.5 times higher than their civilian counterparts (Department of Veterans Affairs, Veterans Health Administration, Office of Suicide Prevention 2018). In 2013, it was estimated that suicide cost the US economy $\$ 58.4$ billion dollars (Shepard et al. 2016); in 2017, the American Foundation for Suicide Prevention (AFSP) put the average cost of suicide at $\$ 69$ billion annually (American Foundation for Suicide Prevention 2016), the Centers for Disease Control (CDC) estimated it to be closer to $\$ 70$ billion (Stone et al. 2018). If economic burden to society seems like a particularly antiseptic measure of the personal tragedy that is suicide, consider the burden experienced by American families. Evaluating 2017 National Survey of Drug Use and Mental Health data, the AFSP estimates that in addition to 47,173 successful suicide attempts, 1,400,000 Americans attempted suicide by various means, $0.6 \%$ of the total population. A 2004 Gallup Youth survey found that nearly half of all 13-17 year olds reported that they personally knew a peer who had attempted suicide (McMurray 2004). After a decade and a half of continuous conflict, active duty veterans experience a 56\% increased risk of suicide, and reserve/National Guard veterans a $29 \%$ increased risk of suicide (Bullman, Schneiderman, and Bossarte 2018). Statistics like these demonstrate the ubiquitousness of suicide in the experience of everyday Americans.

Surprisingly, given how many lives it touches, social explanations for the phenomenon of suicide remains largely opaque in previous literature. Despite broad calls 
for a public health approach to suicide prevention that acknowledges its complex and intersectional nature, the vast majority of efforts focus on identifying and connecting individuals demonstrating high risk behavioral traits with social services and on preventing reattempts (Stone et al. 2018). While highly visible factors such as mental health and substance abuse are known contributors to suicide, they are by no means the only ones. Indeed, rather than stemming from a single cause, suicidality exists within a constellation of known exacerbating factors, financial issues, interpersonal relationships, conduct and anxiety disorders, and access to lethal means to name but a few. The complexity and social nature of suicide act in concert to obscure the mechanisms by which it may be understood, and require an approach unique among the predominant causes of mortality. To that end, researchers, particularly those in the fields of social science, tend to ground their analyses in comparative metrics - such and such group, which exhibits such and such trait, commits suicide at a lower rate than another group which does not exhibit that trait, for example, which may be indicative of a protective factor arising from that trait. In this fashion, several protective and injurious traits have been identified - among them, women attempt suicide at higher rates than men, men are more often successful in the attempt; African Americans attempt suicide far less than whites, members of First Nations far more; divorced individuals attempt suicide successfully more often than married individuals, and so on.

Given these associations, it would seem that suicide should be equally distributed across a population, with any variance observed due to the traits exhibited by specific groups within that population. Unfortunately, this is not the case. US suicide rates have long been observed to exhibit regional variation unexplained by the individual 


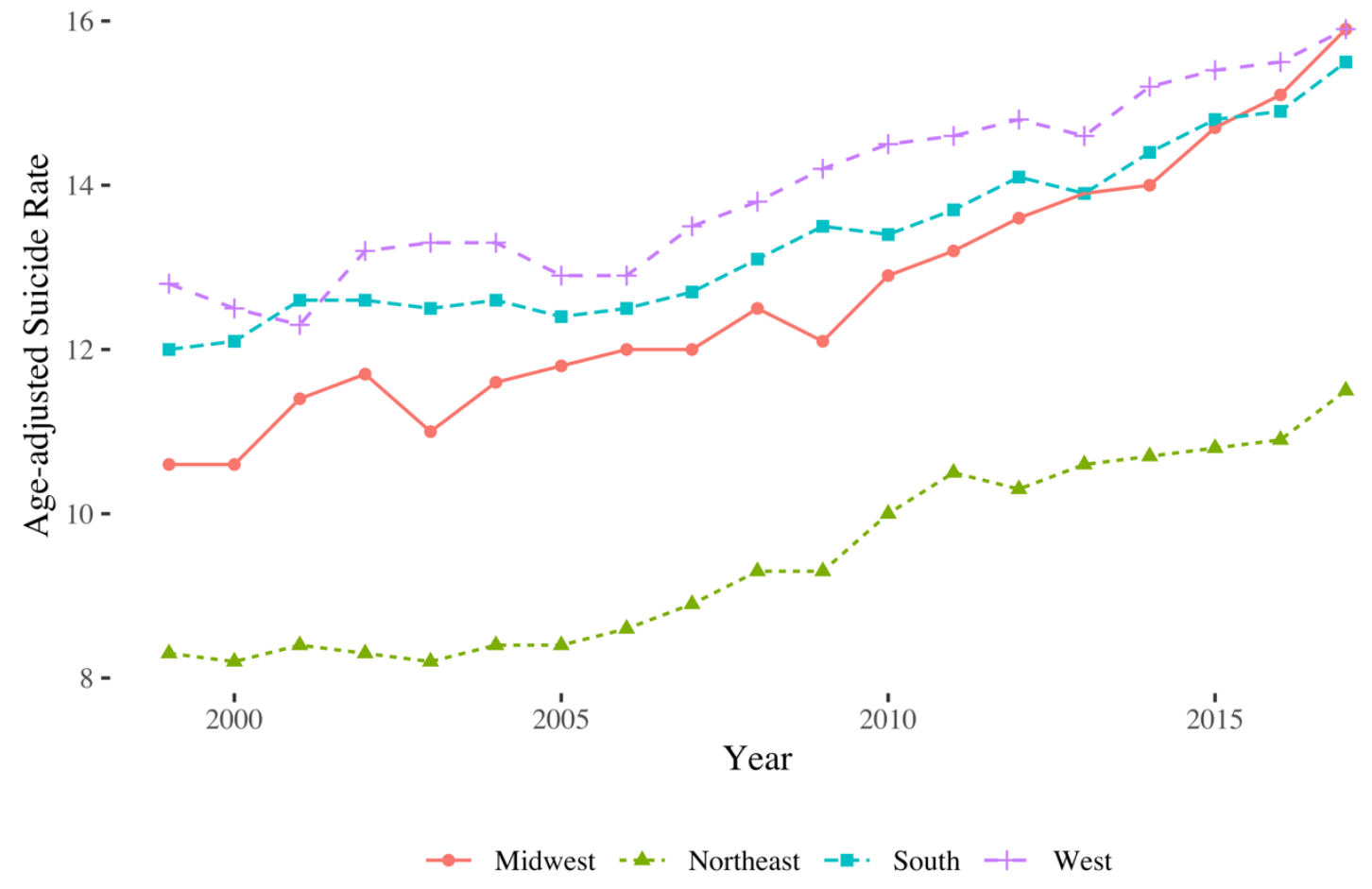

Figure 1. Age-adjusted suicide rate by US Census Region, 1999-2017. (source: CDC WONDER)

characteristics of their respective populations (Centers for Disease Control and Prevention 1997). Regional suicide rates between 1999 and 2017 are represented in Figure 1. The US Census recognizes four major 'regions': the Northeast, Midwest, South, and West. On the whole, it is clear that the rates have been increasing over the years in all the regions. However, while the rate in the Midwest has been increasing more rapidly, the West region demonstrates the highest age-adjusted suicide rate, followed by the South, the Midwest, and the Northeast regions, respectively. These four regions are further subdivided into nine 'divisions': the New England, Middle Atlantic, East North Central, West North Central, South Atlantic, East South Central, West South Central, Mountain, and Pacific. Figure 2 shows the respective age-adjusted suicide rates from each of these regions between 1999 and 2017. Note the stark relief between the Mountain Division and the other eight Census 


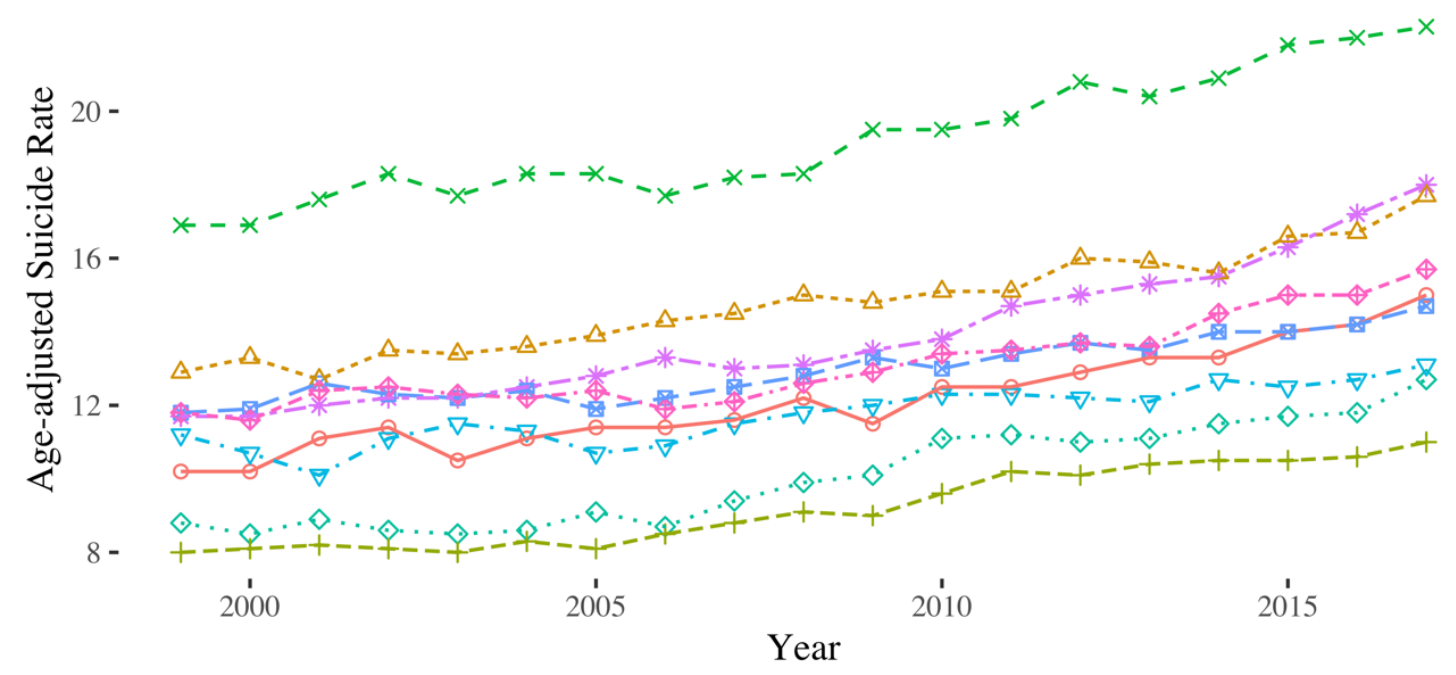

$\begin{array}{lll}- \text { East North Central }-\triangleq \cdot \text { East South Central } & -+\cdot \text { Middle Atlantic } \\ -\times- \text { Mountain } & \cdot \diamond \cdot \text { New England } & \cdot \nabla \cdot \text { Pacific } \\ -\varangle-\text { South Atlantic } & -* \cdot \text { West North Central } \cdot \bullet \cdot \text { West South Central }\end{array}$

Figure 2. Age-adjusted suicide rate by US Census Division, 1999-2017. (source: CDC WONDER)

divisions. Formed by the states of Arizona, Colorado, Idaho, Montana, Nevada, New Mexico, Utah, and Wyoming, the Mountain Division suffers from an age-adjusted suicide rate $75 \%$ higher than the next highest division. All eight of the states comprising the Mountain Division are among the top ten highest state-level suicide rates in the nation, and have been consistently for, as Figure 3 demonstrates, at least the past twenty years, though some sources chart this pattern back to the 19th century (Pepper 2017). Any viable explanation for US suicide rates must be able to account for the differential rates across these geographic areas.

Numerous scholars have examined this areal disparity in the suicide rate of US regions (Baller and Richardson 2002; Barkan, Rocque, and Houle 2013; Breault 1986; Centers for Disease Control and Prevention 1997; Harper, Yang, and Lynch 2008; Lester 


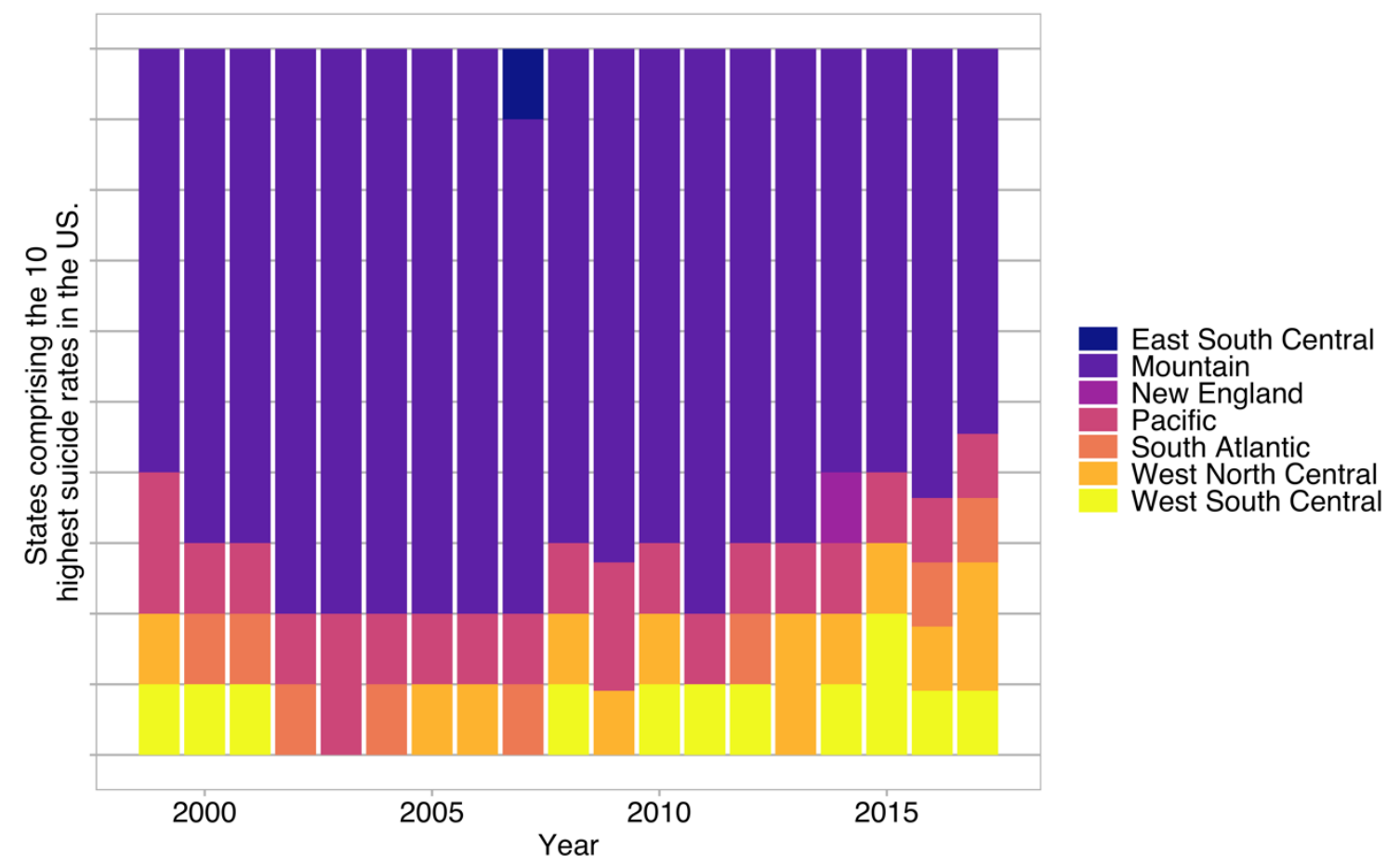

Figure 3. States with the 10 highest suicide rates by US Census Division, 1999-2017. (source: CDC WONDER)

1995, 1996; and Pepper 2017 among others), with decidedly mixed or contradictory findings. A few have despaired of ever finding an satisfactory answer (Pepper 2017), while others have suggested that social characteristics may explain the suicide rate better in urban areas - the non-metropolitan being better left to the attention of those interested in 'psychological or personality variables' (Kowalski, Faupel, and Starr 1987:97) such as psychologists and social workers. Indeed, it is striking how little progress towards understanding has been made in over a century's worth of sociological study. As will be discussed below in more depth, researchers seized upon a formulation of social integration that limited their inquiries in substantive ways, as well as suffering from a paucity of applicable data. In light of these difficulties, scholars have yet to fully articulate the factors 
thought to be causally linked to suicide rates and exhibit no small amount of disagreement with regard to the best ways in which to capture these factors in an analysis.

The present work seeks to contribute to the suicide literature by evaluating the explanatory power of three of the leading sociological theories with regard to suicide rates. To that end, this analysis asks which, if any, of the current sociological theories on suicide best reflects the reality of suicide experienced by Americans in different socio-cultural and socio-historical spheres across the country and, by so doing, hopes to establish the beginnings of a 'best practices' set of tools by which these realities can be captured. In order to do so, however, we must first understand the current state of the literature with regard to suicide, a topic to which we turn in the next section. 
Literature Review

The literature on suicide is almost as multi-faceted as its subject. Proposed causal mechanisms for suicide range from the intensely personal to the macro-social. Interest in the subject has waxed and waned across decades. In this section, we will explore the historical evolution of suicidological theory and will attempt to establish the current state of theory in the field.

In the last decade, the most productive theoretical model of suicide has come to be called the 'ideation-to-action' framework. There are a number of ideation-to-action theories, of which the Three Step (3ST) theory of suicide (Klonsky and May 2015) or O'Connor's Integrated Motivational-Volitional Model (IMVM) (2011) are but two of the more well-known. While these theories vary in form, structure, and emphasis, they are all shaped by the framework laid out in Thomas Joiner's Interpersonal Theory of Suicide (Joiner 2005; van Orden et al. 2010). Joiner's fundamental insight was to envision suicide not as an act, but as a process, one that moves between the dipoles of suicidal ideation and suicide attempt. Joiner realized that contemporaneous theories of suicide had, in focusing on the act of suicide, overlooked two crucial factors. First, suicide attempts do not occur in a vacuum, nor, generally, are they spontaneous events. Rather, they are most often conscious, pre-meditated actions that involve emotional response and planning. Joiner noted that this pool of potential suicides, people involved in ideating or planning suicides, were completely unaddressed by theories responding to the act itself. What pushed an individual from mere passing thoughts of suicide to acting on a suicide plan? Second, Joiner observed that the least optimal moment to intervene in a suicide attempt is after it 
happens. Yet, the vast literature on suicide tended to treat it as a binary event, forcing treatment models into a response stance, rather than advocating for an upstream preventative approach.

Joiner's insights allowed theorists to unpack the process of suicide into various stages progressing along the spectrum between ideation and attempt. This approach encouraged theorists to investigate the various influences at each stage, rather than trying to locate a single causal mechanism. One of the more successful theories to do so is the aforementioned 3ST theory of Klonsky and May (2015). In contrast to O'Connor's IMVM, 3ST sites individuals within a larger social context and allows for a more holistic conceptualization of the movement from ideation to action. 3ST envisions suicidal ideation and suicide attempts as distinct stages mediated by an individual's level of social connectedness: high levels of social integration may extend protective benefits against implementation to individuals with even extremely elevated levels of pain and hopelessness. In this framework the movement between suicide ideation and suicide attempt relies primarily on four factors: pain, hopelessness, connectedness, and capacity. According to Klonsky and May (2015), in the first stage, persistent pain (either emotional or physical) combines with hopelessness (the inability to envision a future state without pain) to spur the development of suicidal ideation. Far from a deterministic process, not everyone who contemplates suicide is moved to action. Transitioning from occasional to a moderate or from moderate to strong levels of ideation is largely a function of social integration, or connectedness. Individuals with high levels of pain and hopelessness may be able to draw upon the role they play in their job or community, or close interpersonal 


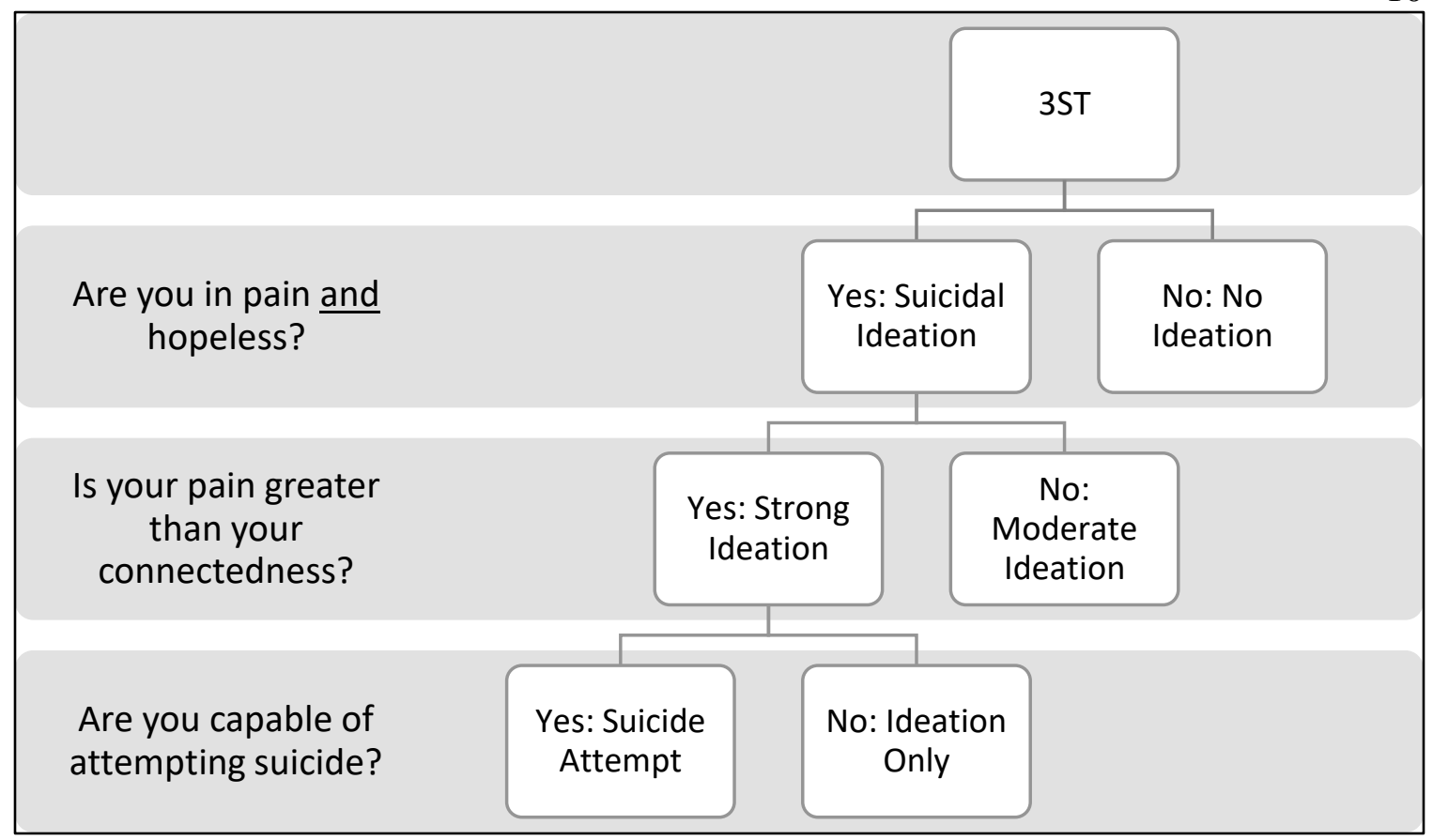

Figure 4. Illustration of the 3ST theory of suicide. (source: Klonsky and May 2015)

ties with family and friends in order to never act on their ideation. Conversely, individuals without a highly developed web of social connections may be more inclined to move from an ideational state to an active state. Finally, dispositional, acquired, and practical capabilities (e.g. individual pain tolerance, access to firearms, etc.) enable suicide attempters to various degrees. This process is depicted in Figure 4.

The work of ideation-action theorists represents a crucial breakthrough in unpacking the complex process of suicidality, but it tends to focus heavily on the first stage, that of individual impetus, and presume the workings of the latter two stages. Here, though, is where the sociological literature on suicide comes into its own. It is a widely held supposition that the degree to which an individual is connected to their community is directly related to their propensity to suicide, but how to conceptualize or measure this 'connection' remains a matter of debate. Broadly speaking, the literature falls into one of 
three schools of thought - in the current work, they will be referred to as the compositional, the ecological, and the demographic - which we will now proceed to explore. These terms are the author's and are used primarily to differentiate the differing conceptualizations for purposes of this analysis. 'Demographic' encapsulates approaches to social integration that are primarily concerned with shifts in population, population movement, and the constitution of populations. 'Compositional' refers to approaches to social integration that treat structural factors of the population occupying a space as the determinative predictors of suicide. Finally, 'ecological' references conceptualizations of social integration that attempt to look at the interplay of the many factors comprising the social field.

\section{Compositional Theories of Social Integration}

The idea that suicide is related to social integration is not a new one. Emile Durkheim's seminal work, Suicide (1897/1951), established a direct correlation between suicide and religious adherence rates in Western Europe in order to demonstrate that "suicide varies inversely with the degree of integration of the social groups of which the individual forms a part." (1999:209) This assertion, combined with Durkheim's choice of non-secular subject matter, spawned what some have referred to as 'Sociology's One Law' (Faupel, Kowalski, and Starr 1987), namely, that Protestants commit suicide at higher rates than Catholics. For better or worse, this Protestant/Catholic comparison would guide most sociological debate on the issue of suicide and social integration for most of the next century (Stack 2000a, 2000b; Wray, Colen, and Pescosolido 2011).

Scholarship in the 1990s broke out of this Protestant/Catholic debate, reconceptualizing the impact of religion on social integration as a unique set of reciprocal 
ties between individuals (Pescosolido 1990; Pescosolido and Georgianna 1989; Pescosolido and Mendelsohn 1986) that can be captured as a sort of 'market share' - a measure of the overall shared ideology and experiences of the population in a given area (Ellison, Burr, and McCall 1997). The work of Bernice Pescosolido was crucial in redirecting sociological inquiry into the nature of suicide away from a focus on the Catholic/Protestant binary and towards a more holistic perspective. Pescosolido developed a network theory of suicide that envisioned religion as a specialized social network, rather than holding it apart as a sort of different-type of social institution. In doing so, Pescosolido advocated a move back to the original Durkheimian framing; a move that allowed her and her co-authors to re-site religion within surrounding systems of social organization. Working in conjunction with other social institutions like schools, clubs, hospitals and the like, religion connected individuals and embedded them within a larger, protective social sphere. In Pescosolido's conception, religious adherence could be measured alongside other social factors in order to develop an understanding of the level of integration of a given society - higher levels would result in lower suicide rates. The application of network theory in this manner was not dependent upon denomination, was easily replicated in crossnational studies, and allowed for conceptual movement between the micro-, meso-, and macro-social levels (Barranco 2016; Hsieh 2017).

Ecological Theories of Social Integration

Pescosolido's influence in re-framing sociological inquiry into suicide did not end with pushing scholarship to move beyond the Catholic/Protestant binary. It prompted some scholars of social integration to move beyond a focus on religion altogether. Robert 
Putnam's widely-regarded work on social capital (2000), or 'the collective civic value of social networks' (Kushner and Sterk 2005), was quickly seized upon by scholars of public health and mortality. Social capital theorists assert that tighter civic bonds result in higher levels of social capital and, as a result, lower levels of suicide, non-suicide mortality, and other negative health outcomes (Turner 2003). Ichiro Kawachi's work, in particular, has been crucial in demonstrating the link between income inequality, level of social integration, and mortality (Kawachi 1997; Kawachi et al. 1997). The lone study that investigated social capital and suicide rate found strong and intriguing associations, particularly for white men and women, but oddly neglected to account for religion at all and was conducted at the state-level with little regard for regional or divisional variation (Smith and Kawachi 2014). The association between social capital and suicide remains largely unexplored in the quantitative literature. In a sense, one can view the argument for the connection between social capital and suicide rate as merely an extension of the arguments put forward in favor of the relationship between religion and suicide rate: closer social ties exert protective effects against suicide. The social capital framework places religion alongside civic and secular organizations in the social sphere. Interestingly, this re-siting of religion back into the social fabric was suggested by the work of van Tubergen et al. (2005) in testing Pescosolido's theories, but the authors seemingly failed to fully realize the implications of their findings.

Demographic Theories of Social Integration

Unfortunately, the aforementioned theorists cannot account for the fact that US suicide rates demonstrate pronounced regional variation that remains unexplained by 
psychological, biological, or religious factors (Centers for Disease Control and Prevention 1997; Ellison et al. 1997; Pepper 2017). The previously discussed suicide rates in the American Mountain West, in particular, have exhibited elevated suicide rates for so long that some researchers have begun to refer to a US "suicide belt" (Harper et al. 2008). This region, running along a corridor that parallels the Rocky Mountains, is roughly analogous to the 'Mountain Division' of the US Census. Noting disparate regional suicide rates (as depicted in Figures 1 and 2), Barkan, Rocque, and Houle explain the discrepancy by focusing on a neglected aspect of the social integration paradigm: population stability (2013). Theorizing that populations that undergo less disruptive demographic shifts are apt to have stronger social institutions and, thus, higher rates of social integration, Barkan et al. developed a measure that combined population density with inter-unit population shift. This approach has the benefit of avoiding the subjective nature of constructing a measure of social institutions as it relies exclusively on data regarding the movement of populations. Barkan et al. focus on an aggregated index they term 'residential stability', and, alongside more general measures of demographic change, demonstrate its explanatory value in models examining the differential in Western US suicide rates.

Hypotheses

The goal of this analysis is to comparatively evaluate the utility of the above three theoretical frames in understanding the nature of suicide in the United States. To that end, I stipulate: 
Hypothesis 1. According to compositional theories of social integration, religious homogeneity, or the level to which there exists a shared faith within a county, will predict suicide rates.

Hypothesis 2. According to ecological theories of social integration, social capital, or the level of social connectedness within a county, will predict suicide rates.

Hypothesis 3. According to demographic theories of social integration, residential stability, or the level of population change within a county, will predict suicide rates. 
Data and Methods

Data are aggregated from multiple sources. First, data on suicides were obtained from the Centers for Disease Control's (CDC) National Center for Health Statistics (NCHS). Second, data on the majority of controls, and residential stability were gathered from the 2000 and 2010 US Decennial censuses. Third, data on religion were gathered from the Association of Statisticians of American Religious Bodies, Longitudinal Religious Congregations and Membership file. Finally, data on social capital were gathered from the Penn State Northeast Regional Center for Rural Development.

Though the CDC makes national mortality data publicly available through its online WONDER portal ${ }^{1}$, rates for sub-national geographic areas are suppressed when that data represents 9 or fewer deaths or when the corresponding denominator represents a population fewer than $10 .^{2}$ Due to these restrictions, sub-national US analyses tend to rely on the Statistical Metropolitan Service Area (SMSA) as the unit of analysis (Bainbridge 1989; Breault 1986; Burr, Hartman, and Matteson 1999; Burr, Mccall, and Powell-Griner 1994; Ellison et al. 1997; Stark, Doyle, and Rushing 1983; Wadsworth and Kubrin 2007). While this approach circumvents data availability issues, the use of SMSAs eliminates nonmetropolitan spaces from analysis and over-represents the heterogeneity of social spaces (Faupel et al. 1987). For these reasons, this analysis sought and was granted special access to the CDC's Multiple Cause of Death (MCD) data file (National Center for Health Statistics 2019).

\footnotetext{
${ }^{1}$ https://wonder.cdc.gov

${ }^{2}$ For more information, please see https://wonder.cdc.gov/wonder/help/mcd.html.
} 
The MCD dataset contains the information found on every death certificate filed in the fifty states, District of Columbia, and assorted US Territories for the years 1999-2010. For each individual represented, the MCD records age, sex, marital status, race, ethnicity, education level, up to 20 causes of death, and county-level geographic information. After decryption, observations for individuals in all US Territories (Puerto Rico, the Virgin Islands, and Guam, $\mathrm{n}=13$ ) were removed as well as any observations missing geographic information. Individual age was determined to the year and 5-year age category bins were assigned to each observation. Pre-teens and teenagers (age < 20) were removed in order to de-bias demographic information such as education level and unemployment status, and, as the data is top-coded by the NCHS for ages 85 and above (age > 84), these individuals were similarly excised. Finally, the subset of all observations that listed any of the ICD-10 codes for suicide (ICD-10 codes U03.0, U03.9, X60-X84, \& Y87.0) as the primary 'Underlying Cause of Death' were selected for a preliminary sample of 397,449 individuals. The ICD-10 codes were then categorized into 10 groups of like causes (e.g. Poisoning by various causes, drowning, struck by or in a moving vehicle, etc.). Complete descriptive statistics for the MCD sample are found in Table 1.

The observations were then summed by FIPS code in order to aggregate the data to the county-level $(n=3,041)$. This analysis uses US counties as its primary unit of analysis for several reasons. First, in order to further de-identify individuals. Second, counties are the most homogenous geographical unit available, thereby minimizing the risk of aggregation bias (Faupel et al. 1987). Third, the use of counties allows for the inclusion of all levels of urbanity, not just metropolitan areas. Finally, county-level data is available for 
all predictors of interest and controls for the years under consideration. FIPS codes also provided a convenient framework by which both predictors of interest and control variables were associated with the MCD data.

Because suicide is a relatively rare event, many counties, particularly those with low population levels, display a high amount of volatility with regard to suicide mortality. In order to smooth this volatility, observed deaths were summed for each county for the years $2006-2010(\mathrm{n}=164,283$ individuals $)$ and this average assigned to each county as its suicide mortality for the end year, a common methodological practice in suicide literature (Barranco 2016; Burr et al. 1999; Cutchin and Churchill 1999; Wadsworth and Kubrin 2007). Table 1 provides complete descriptive statistics on the MCD sample.

Key Predictors

Social capital was assessed via Penn State's Northeast Regional Center for Rural Development (NERCRD) County-level Measure of Social Capital (Rupasingha, Goetz, and Freshwater 2006). This aggregate measure captures four factors of social integration within a county: (1) voter turnout in the previous presidential election, (2) the census response rate, (3) the number of non-profit organizations (not including those with an international focus), and (4) the proportion of religious organizations, civic and social associations, business associations, political organizations, professional organizations, labor organizations, bowling centers, fitness and recreation centers, golf courses and country clubs, and sports teams and clubs, summarized and divided by the population per 1,000 . These four factors are then standardized to have a mean of zero and a standard 
Table 1. Sociodemographic Characteristics of Suicide Mortality Data from National Center for Health Statistics

\begin{tabular}{|c|c|c|c|c|c|}
\hline & $\mathbf{n}$ & $\begin{array}{c}\text { Mean/ } \\
\text { Proportion }\end{array}$ & $\begin{array}{l}\text { Standard } \\
\text { Deviation }\end{array}$ & Minimum & Maximum \\
\hline \multicolumn{6}{|l|}{ Demographic Data } \\
\hline \multicolumn{6}{|l|}{ Sex } \\
\hline Female & 35,293 & 0.21 & & 0 & 1 \\
\hline Male & 130,348 & 0.79 & & 0 & 1 \\
\hline Age & 165,641 & 47.1 & 15.77 & 20 & 84 \\
\hline \multicolumn{6}{|l|}{ Age Category } \\
\hline 20-24 & 13,630 & 0.08 & & 0 & 1 \\
\hline $25-29$ & 13,647 & 0.08 & & 0 & 1 \\
\hline $30-34$ & 12,971 & 0.08 & & 0 & 1 \\
\hline $35-39$ & 15,431 & 0.09 & & 0 & 1 \\
\hline $40-44$ & 17,833 & 0.11 & & 0 & 1 \\
\hline $45-49$ & 20,793 & 0.13 & & 0 & 1 \\
\hline $50-54$ & 20,095 & 0.12 & & 0 & 1 \\
\hline $55-59$ & 16,217 & 0.10 & & 0 & 1 \\
\hline $60-64$ & 11,092 & 0.07 & & 0 & 1 \\
\hline $65-69$ & 7,599 & 0.05 & & 0 & 1 \\
\hline $70-74$ & 5,916 & 0.04 & & 0 & 1 \\
\hline $75-79$ & 5,683 & 0.03 & & 0 & 1 \\
\hline $80-84$ & 4,734 & 0.03 & & 0 & 1 \\
\hline \multicolumn{6}{|l|}{ Race \& Ethnicity } \\
\hline Non-Hispanic White & 139,589 & 0.84 & & 0 & 1 \\
\hline Non-Hispanic Black & 8,974 & 0.05 & & 0 & 1 \\
\hline Non-Hispanic Asian & 4,116 & 0.03 & & 0 & 1 \\
\hline Non-Hispanic First Nations & 1,628 & 0.01 & & 0 & 1 \\
\hline Hispanic & 10,837 & 0.07 & & 0 & 1 \\
\hline NA & 497 & 0.00 & & 0 & 1 \\
\hline
\end{tabular}


Table 1. Population Characteristics con't.

Standard

n Mean Deviation Minimum Maximum

Demographic Data con't.

Marital Status

Single

Married

48,840

0.29

64,114

0.39

Divorced

Widowed

39,980

0.24

9,546

0.06

Unknown

3,161

0.02

$\begin{array}{ll}0 & 1 \\ 0 & 1 \\ 0 & 1 \\ 0 & 1 \\ 0 & 1\end{array}$

\section{Education}

$<$ High School

High School

Some College

$>=$ College

NA
24,601

68,173

36,470

28,896

7,501
0.15

0.41

0.22

0.17

0.05

1

1

\section{Areal Data}

Urban Status

\begin{tabular}{|c|c|c|c|}
\hline Large Central Metro & 42,883 & 0.26 & 0 \\
\hline Large Fringe Metro & 37,273 & 0.23 & 0 \\
\hline Medium Metro & 36,478 & 0.22 & 0 \\
\hline Small Metro & 17,861 & 0.11 & 0 \\
\hline Micropolitan (Nonmetro) & 17,651 & 0.11 & 0 \\
\hline NonCore (Nonmetro) & 13,481 & 0.08 & 0 \\
\hline
\end{tabular}

\section{Division}

\begin{tabular}{|c|c|c|c|c|}
\hline New England & 6,435 & 0.04 & 0 & 1 \\
\hline Middle Atlantic & 16,523 & 0.10 & 0 & 1 \\
\hline East North Central & 23,943 & 0.14 & 0 & 1 \\
\hline West North Central & 11,509 & 0.07 & 0 & 1 \\
\hline South Atlantic & 33,956 & 0.20 & 0 & 1 \\
\hline East South Central & 11,879 & 0.07 & 0 & 1 \\
\hline West South Central & 18,929 & 0.11 & 0 & 1 \\
\hline Mountain & 17,154 & 0.10 & 0 & 1 \\
\hline Pacific & 25,299 & 0.15 & 0 & 1 \\
\hline
\end{tabular}


Table 1. Population Characteristics con't.

\begin{tabular}{|c|c|c|c|c|c|}
\hline & n & Mean & $\begin{array}{l}\text { Standard } \\
\text { Deviation }\end{array}$ & Minimum & Maximum \\
\hline \multicolumn{6}{|l|}{ Areal Data con't. } \\
\hline \multicolumn{6}{|l|}{ Region } \\
\hline Northeast & 22,958 & 0.14 & & 0 & 1 \\
\hline Midwest & 35,452 & 0.21 & & 0 & 1 \\
\hline South & 64,764 & 0.39 & & 0 & 1 \\
\hline West & 42,453 & 0.26 & & 0 & 1 \\
\hline \multicolumn{6}{|l|}{ ICD-10 Data } \\
\hline X60: Nonopioid Analgesics & 966 & 0.01 & & 0 & 1 \\
\hline $\begin{array}{l}\text { X61: Antiepileptic, } \\
\text { Psychotropic Drugs }\end{array}$ & 4,517 & 0.03 & & 0 & 1 \\
\hline $\begin{array}{l}\text { X62: Narcotics, } \\
\text { Hallucinogens }\end{array}$ & 3,357 & 0.02 & & 0 & 1 \\
\hline $\begin{array}{l}\text { X63: Drugs Acting on the } \\
\text { Nervous System }\end{array}$ & 138 & 0.00 & & 0 & 1 \\
\hline $\begin{array}{l}\text { X64: Other, Unspecified } \\
\text { Drugs }\end{array}$ & 14,971 & 0.09 & & 0 & 1 \\
\hline X65: Alcohol & 197 & 0.00 & & 0 & 1 \\
\hline X66: Organic Solvents & 604 & 0.00 & & 0 & 1 \\
\hline X67: Other Gases, Vapours & 5,632 & 0.03 & & 0 & 1 \\
\hline X68: Pesticides & 65 & 0.00 & & 0 & 1 \\
\hline $\begin{array}{l}\text { X69: Other, Unspecified } \\
\text { Chemicals }\end{array}$ & 435 & 0.00 & & 0 & 1 \\
\hline $\begin{array}{l}\text { X70: Hanging, } \\
\text { Strangulation, Suffocation }\end{array}$ & 37,939 & 0.23 & & 0 & 1 \\
\hline X71: Drowning, Submersion & 1,837 & 0.01 & & 0 & 1 \\
\hline X72: Handgun Discharge & 19,127 & 0.12 & & 0 & 1 \\
\hline $\begin{array}{l}\text { X73: Rifle, Shotgun, Larger } \\
\text { Firearm Discharge }\end{array}$ & 13,082 & 0.08 & & 0 & 1 \\
\hline $\begin{array}{l}\text { X74: Unspecified Firearm } \\
\text { Discharge }\end{array}$ & 51,539 & 0.31 & & 0 & 1 \\
\hline X75: Explosive Material & 19 & 0.00 & & 0 & 1 \\
\hline X76: Smoke, Fire, Flames & 774 & 0.00 & & 0 & 1 \\
\hline $\begin{array}{l}\text { X77: Steam, Hot Vapours, } \\
\text { Hot Objects }\end{array}$ & 2 & 0.00 & & 0 & 1 \\
\hline X78: Sharp Object & 3,363 & 0.02 & & 0 & 1 \\
\hline X79: Blunt Object & 2 & 0.00 & & 0 & 1 \\
\hline
\end{tabular}


Table 1. Population Characteristics con't.

\begin{tabular}{|c|c|c|c|c|c|}
\hline & n & Mean & $\begin{array}{l}\text { Standard } \\
\text { Deviation }\end{array}$ & Minimum & Maximum \\
\hline \multicolumn{6}{|l|}{ ICD-10 Data con't. } \\
\hline $\begin{array}{l}\text { X80: Jumping, Falling from High } \\
\text { Place }\end{array}$ & 3,363 & 0.02 & & 0 & 1 \\
\hline $\begin{array}{l}\text { X81: Jumping, Lying before } \\
\text { Motor Vehicle }\end{array}$ & 1,493 & 0.01 & & 0 & 1 \\
\hline $\begin{array}{l}\text { X82: Intentional Collision of } \\
\text { Motor Vehicle }\end{array}$ & 551 & 0.00 & & 0 & 1 \\
\hline $\begin{array}{l}\text { X83: Intentional Self-harm, } \\
\text { Other Means }\end{array}$ & 778 & 0.00 & & 0 & 1 \\
\hline $\begin{array}{l}\text { X84: Intentional Self-harm, } \\
\text { Unspecified Means }\end{array}$ & 823 & 0.01 & & 0 & 1 \\
\hline $\begin{array}{l}\text { Y870: Sequelae of Intentional } \\
\text { Self-harm }\end{array}$ & 346 & 0.00 & & 0 & 1 \\
\hline
\end{tabular}


deviation of one and subjected to principal components analysis. The first principle component is considered the index of social capital. Data were collected for the year 2009.

Religious homogeneity was captured using a methodology informed by Ellison et al (1997). Rates of religious adherence were gathered for each major religious tradition (Evangelical Protestant, Mainline Protestant, Catholic, African American Protestant, Orthodox, and Other) in each county for 2010 via the Glenmary Research Center and Association of Statisticians of American Religious Bodies' (ARDA) Longitudinal Religious Congregations and Membership File (LRCM), 1980-2010 (Bacon, Finke, and Jones 2018). Ellison et al demonstrated that religious homogeneity could be captured using the Herfindahl-Hirschman Index (HHI), a measure traditionally applied to assess market capture or 'share' in economics. The traditional HHI measure takes the form:

$$
H H I_{j}=\sum_{i=1}^{K}\left(\frac{p_{i j}}{P_{r j}}\right)^{2}
$$

where, for our purposes, $\mathrm{p}_{\mathrm{i}}$ represents the number of adherents for religious tradition $i$ in county $j, \mathrm{P}_{\mathrm{r}}$ represents the overall population of religious adherents in county $j$, and $K$ represents the number of religious traditions in county $j$. The HHI may range from $1 / \mathrm{K}$ to one and represents the probability of any two randomly selected religious adherents being from the same religious tradition. For example, a county with a population of 100 people, 50 of whom belong to religious denomination A and 50 of whom belong to religious denomination B would have a HHI of $(50 / 100)^{2}+(50 / 100)^{2}$ or $(0.25)+(0.25)$ or HHI $=$ 0.50 - a $50 \%$ probability of any two randomly selected adherents being from the same denomination. 
In the course of this analysis, two issues arose with regard to the use of the traditional measure per the Herfindahl-Hirschman Index. First, the traditional measure envisions a closed market in which market share must always sum to $100 \%$. For retail goods, this assumption may hold - however, with regard to religiosity, the 'market' is not bounded by the number of believers, but by the population of potential believers. To illustrate, consider a county with a population of 10,000 of whom 50 are adherents of denomination A, 50 are adherents of denomination B, and 9,900 are agnostic or atheist. This county would have an identical HHI to that of the county in the prior example, despite the obvious differential between possible religious influence. In order to capture the overall influence of religion within counties, this analysis trades the total population of religious adherents in the denominator for the total county population, as represented by the following:

$$
H H I_{j}=\sum_{i=1}^{K}\left(\frac{p_{i j}}{P_{j}}\right)^{2}
$$

This alteration to the traditional HHI formula brought about a second difficulty. The traditional HHI represents a proportion of a bounded whole but, for good or ill, counties are not autonomous units that function independently of one another. With regard to counties with small populations, the overall number of adherents claimed by denominations within the county may be higher than the actual population of the county, resulting in an $\mathrm{HHI}$ that ranges from $1 / \mathrm{K}$ to infinity. Consider a rural county that hosts a church that services believers from several of the surrounding counties. The church may report a count of believers higher than the population of its host county, resulting in 
uninterpretable results for the calculation of religious 'market share'. Though we may no longer be able to directly interpret the calculated HHI's in this analysis as probabilities, it was decided to retain them as accurate representations of religious influence within the county unit.

This analysis follows and extends Barkan et al. (2013) in constructing a measure of residential stability. Two variables from the 2000 and 2010 decennial Census were summed in order to calculate the percentage change in the overall number of households in a given county for the decade. The proportion of individuals over the age of five who lived in the same house a year earlier was then gathered from the American Community Survey's (ACS) 2010 5-year estimates. Both metrics were then standardized and summed in order to create the cumulative measure for residential stability $(\mathrm{CR}=0.074)$.

\section{Controls}

Controls are an assortment of sociodemographic variables identified in the previous literature as being associated with suicide rates. Selection focus was on accounting for factors that represent individual characteristics: proportion male, median age, proportion veteran, proportion African American, proportion First Nations, and proportion Hispanic, as well as percent divorced, rate of alcoholism and opioid abuse, and prevalence of mental illness (Stone et al. 2018). Other potential correlates included indicators of the socioeconomic position of residents (proportion unemployed, proportion below $150 \%$ of the Federal Poverty Level, and the Gini Index of Income Inequality) (Agerbo, Sterne, and Gunnell 2007), percent Catholic and percent Evangelical Protestant adherents (Burr et al. 1994), and proportion of county residents who listed their occupation as farm worker 
(Ringgenberg et al. 2018). The majority of control variables were gathered from the 2010 ACS 5-year estimates. Proportion of Catholic and Evangelical Protestant adherence was collected from the ARDA LRCM data. Mortality resulting from alcoholism and opioid abuse, depression, bipolar disorder, schizophrenia, and firearms were computed from 5year mortality averages taken from the MCD dataset and were evaluated with regard to multicollinearity by calculating variance inflation factors for the entire pool of potential controls (separate, unreported analysis). Controls were 'binned' according to their relative effect: demographic, environmental, and traumatic, and evaluated for redundancy. Selected controls were chosen from each bin to represent each facet of the social experience. A dummy representing rurality was constructed which flagged counties labeled as either 'Micropolitan (nonmetro)' or 'Non-core (nonmetro)' according to the NCHS 2013 UrbanRural Classification Scheme for Counties. Finally, a dummy variable was added that flagged counties of the Mountain Division, in order to control for the statistically high rates of suicide within that region. Descriptive statistics for the entire selection of model variables are presented in Table 2.

Analytic Models

A number of analytic models were considered in order to evaluate the relationship between suicide mortality and the predictors of interest. It should be noted that attempts were made to fit the model to estimated Ordinary Least Squares, Poisson, and quasi-Poisson distributions; the negative binomial demonstrated the best fit and was selected for this analysis. The negative binomial distribution is highly appropriate due to the count nature of the dependent variable as well as its overall rarity and tendency towards overdispersion. 
Previous work has limited analysis to merely identifying correlations between predictor and outcome variables (e.g. Pepper 2017), but in the present analysis regression methods are used to more efficiently estimate the various social influences on suicide rates. Though the measure of age-adjusted suicide mortality used here is a five year average, it is representative of the entire population of suicides in the US from 2006-2010. Despite this, tests of significance remain necessary to assess the probability of random fluctuations as well as to gauge the 'average' effect of the predictor variables on the outcome across the time period. 
Table 2. County Level Descriptive Statistics (Source: National Center for Health Statistics, US Census, ARDA, NERCRD)

\begin{tabular}{|c|c|c|c|c|c|}
\hline & $\mathbf{n}$ & Mean & $\begin{array}{l}\text { Standard } \\
\text { Deviation }\end{array}$ & Minimum & Maximum \\
\hline Suicide Rate & 3,146 & 14.5 & 10.4 & 0.00 & 80.1 \\
\hline Social Capital & 3,146 & 0.00 & 1.34 & -3.93 & 17.4 \\
\hline Religious Homogeneity & 3,146 & 0.17 & 0.14 & 0.00 & 1.74 \\
\hline Residential Stability & 3,146 & 0.00 & 1.25 & -12.9 & 4.81 \\
\hline$\%$ Male & 3,146 & 0.50 & 0.03 & 0.43 & 0.76 \\
\hline Median Age & 3,146 & 39.8 & 4.86 & 21.7 & 62.5 \\
\hline$\%$ African American & 3,146 & 0.09 & 0.15 & 0.00 & 0.86 \\
\hline$\%$ First Nations ${ }^{1}$ & 3,146 & 0.74 & 0.44 & 0.00 & 1.00 \\
\hline$\%$ Hispanic & 3,146 & 0.08 & 0.13 & 0.00 & 0.98 \\
\hline$\%$ College Degree & 3,146 & 0.13 & 0.06 & 0.03 & 0.52 \\
\hline$\%$ Occupation: Farmer & 3,146 & 0.02 & 0.03 & 0.00 & 0.21 \\
\hline \# of Firearm Suicides & 3,146 & 0.60 & 0.22 & 0.00 & 1.00 \\
\hline$\%$ Evangelical Protestant & 3,146 & 0.24 & 0.17 & 0.00 & 1.31 \\
\hline$\%$ Catholic & 3,146 & 0.12 & 0.13 & 0.00 & 1.00 \\
\hline$\%$ Divorced & 3,146 & 0.11 & 0.02 & 0.02 & 0.25 \\
\hline$\%<1.5 x$ Federal Poverty Level & 3,146 & 0.26 & 0.09 & 0.00 & 0.70 \\
\hline$\%$ Veteran & 3,146 & 0.12 & 0.03 & 0.00 & 0.32 \\
\hline \# of Deaths due to Alcoholism & 3,146 & 10.1 & 29.8 & 0.00 & 758 \\
\hline
\end{tabular}

${ }^{1}$ Dichotomized at the 75 th percentile due to high skewness. 
Findings

Table 3 presents the result of Spearman's rho correlations for the outcome, predictor, and control variables. As expected, median age, proportions of the population who are divorced, who are in poverty, who have veteran status, and the two proxies for availability of firearms and substance abuse (\# of firearm suicides and \# of deaths due to alcoholism, respectively) are positively and significantly correlated with age-adjusted suicide rates at the county-level. Additionally, in line with the literature, the proportion of the population identifying as African American, those listing their occupation as farm worker, or identifying as Catholic are significantly and negatively correlated with county-level suicide rates. Gratifyingly, two of the three predictors, social capital and religious homogeneity, are also negatively and significantly associated with the outcome variable. Unexpectedly, residential stability, our third predictor, is not significantly associated with the outcome variable, though it is significantly and negatively correlated with counties in the Mountain Division $(-0.12, \mathrm{p}<.001)$. Also in contravention of expectations generated by the literature, proportion male is negatively correlated with the outcome variable $(\mathrm{p}>.05)$, as is percent of the population identifying as First Nations $(\mathrm{p}<.001)$, those listing farm worker as occupation $(\mathrm{p}<.01)$, and counties identified as either Micropolitan (Nonmetro) or NonCore $($ Nonmetro) $(\mathrm{p}<.01)$. The three predictor variables are significantly correlated with each other, and with the suite of control variables (columns 2, 3, and 4). Social capital is positively correlated with rural counties and with counties in the Mountain Division. Religious homogeneity is also positively correlated with rural counties in general, but is negatively correlated with the counties of the Mountain Division. 
Table 3. Correlation Matrix.

\begin{tabular}{|c|c|c|c|c|c|}
\hline & 1 & 2 & 3 & 4 & 5 \\
\hline \multicolumn{6}{|l|}{ 1. $\mathrm{AAMR}^{1}$} \\
\hline 2. Social Capital Index & $-0.07 * * *$ & & & & \\
\hline 3. Religious Homogeneity & $-0.06^{* *}$ & $0.14 * * *$ & & & \\
\hline 4. Residential Stability & 0.03 & $-0.14 * * *$ & $-0.13 * * *$ & & \\
\hline 5. \% Male & -0.01 & -0.02 & $-0.13 * * *$ & 0.03 & \\
\hline 6. Median Age & $0.07 * * *$ & $0.52 * *$ & $0.09 * * *$ & $0.14 * * *$ & $0.04 *$ \\
\hline 7. \% African American & $-0.05 * *$ & $-0.41 * * *$ & $-0.04 * *$ & $-0.09 * * *$ & $-0.27 * * *$ \\
\hline 8. $\%$ First Nations ${ }^{2}$ & $-0.09 * * *$ & $-0.05 * *$ & $0.07 * * *$ & $0.07 * *$ & $-0.23 * * *$ \\
\hline 9. \% Hispanic & 0.01 & $-0.27 * * *$ & $-0.04 *$ & $-0.07 * * *$ & $0.07 * * *$ \\
\hline 10. \% Divorced & $0.22 * * *$ & $-0.20 * * *$ & $-0.17 * * *$ & $-0.12 * * *$ & -0.02 \\
\hline 11. \% with College Degree & 0.01 & $0.34 * * *$ & $-0.18 * * *$ & $0.07 * * *$ & $-0.13 * * *$ \\
\hline 12. $\%<1.5 x$ Federal Poverty Level & $0.05 * *$ & $-0.33 * * *$ & $0.11 * * *$ & $-0.29 * * *$ & $-0.08 * * *$ \\
\hline 13. \% Veteran & $0.19 * * *$ & $0.27 * * *$ & $-0.13 * * *$ & $0.11 * * *$ & $0.13 * * *$ \\
\hline 14. \% Farmer as Occupation & $-0.06 * *$ & $0.39 * * *$ & $0.42 * * *$ & $-0.09 * * *$ & $0.23 * * *$ \\
\hline 15. \# of Firearm Suicides & $0.10 * * *$ & $-0.05 * *$ & $0.13 * * *$ & 0.01 & 0.01 \\
\hline 16. \% Evangelical Protestant & 0.03 & $-0.12 * * *$ & $0.51 * * *$ & $-0.12 * * *$ & $-0.19 * * *$ \\
\hline 17. \% Catholic & $-0.06 * * *$ & $0.27 * * *$ & $0.08 * * *$ & -0.01 & $0.11 * * *$ \\
\hline $\begin{array}{l}\text { 18. \# of Deaths from Substance Abuse } \\
\text { (alcohol, opioid) }\end{array}$ & $0.13 * * *$ & $-0.30 * * *$ & $-0.27 * * *$ & $0.09 * * *$ & $-0.25 * * *$ \\
\hline 19. Rural Flag & $-0.05 * *$ & $0.31 * * *$ & $0.23 * * *$ & $-0.09 * * *$ & $0.18 * * *$ \\
\hline 20. Division: Mountain Flag & $0.14 * * *$ & $0.04 *$ & $-0.11 * * *$ & $0.06 * *$ & $0.20 * * *$ \\
\hline
\end{tabular}

Note: Spearman's rho rank correlation

${ }^{1}$ Age-adjusted to US Census Bureau 2010 population figures.

${ }^{2}$ Dichotomized at the 75 th percentile due to high kurtosis.

$* \mathrm{p}<.05, * * \mathrm{p}<.01, * * * \mathrm{p}<.001$ 
Table 3. Correlation Matrix con't.

6

\begin{tabular}{|c|c|c|c|c|c|}
\hline \multicolumn{6}{|l|}{ 1. $\mathrm{AAMR}^{1}$} \\
\hline \multicolumn{6}{|l|}{ 3. Religious Homogeneity } \\
\hline \multicolumn{6}{|l|}{ 4. Residential Stability } \\
\hline \multicolumn{6}{|l|}{ 5. \% Male } \\
\hline \multicolumn{6}{|l|}{ 6. Median Age } \\
\hline 7. \% African American & $-0.40 * * *$ & & & & \\
\hline 8. $\%$ First Nations ${ }^{2}$ & -0.01 & $0.25 * * *$ & & & \\
\hline 9. \% Hispanic & $-0.37 * * *$ & $0.18 * * *$ & $-0.16^{* * * *}$ & & \\
\hline 10. \% Divorced & $0.12 * * *$ & $0.09 * * *$ & $-0.07 * * *$ & -0.03 & \\
\hline 11. \% with College Degree & 0.02 & $-0.06 * * *$ & -0.01 & $0.22 * * *$ & $-0.22 * * *$ \\
\hline 12. $\%<1.5 x$ Federal Poverty Level & $-0.13 * * *$ & $0.24 * * *$ & $-0.07 * * *$ & $-0.06 * * *$ & $0.27 * * *$ \\
\hline 13. \% Veteran & $0.53 * * *$ & $-0.26 * * *$ & $-0.16 * * *$ & $-0.13 * * *$ & $0.26 * * *$ \\
\hline 14. \% Farmer as Occupation & $0.39 * * *$ & $-0.49 * * *$ & $-0.12 * * *$ & $-0.20 * * *$ & $-0.14 * * *$ \\
\hline 15. \# of Firearm Suicides & $0.14 * * *$ & 0.03 & -0.03 & $-0.21 * * *$ & $0.14 * * *$ \\
\hline 16. \% Evangelical Protestant & -0.03 & $0.27 * * *$ & $0.13 * * *$ & $-0.06 * * *$ & $0.18 * * *$ \\
\hline 17. \% Catholic & 0.01 & $-0.26 * * *$ & $-0.10 * * *$ & $0.26 * * *$ & $-0.28 * * *$ \\
\hline $\begin{array}{l}\text { 18. \# of Deaths from Substance Abuse } \\
\text { (alcohol, opioid) }\end{array}$ & $-0.34 * * *$ & $0.35 * * *$ & $0.05^{* *}$ & $0.31 * * *$ & $0.08 * * *$ \\
\hline 19. Rural Flag & $0.40 * * *$ & $-0.29 * * *$ & $-0.15 * * *$ & $-0.23 * * *$ & -0.02 \\
\hline 20. Division: Mountain Flag & 0.00 & $-0.27 * * *$ & $-0.30 * * *$ & $0.21 * * *$ & $0.05 * *$ \\
\hline
\end{tabular}

Note: Spearman's rho rank correlation

${ }^{1}$ Age-adjusted to US Census Bureau 2010 population figures.

${ }^{2}$ Dichotomized at the 75 th percentile due to high kurtosis.

$* \mathrm{p}<.05, * * \mathrm{p}<.01, * * * \mathrm{p}<.001$

$\begin{array}{llll}7 & 8 & 9 & 10\end{array}$


Table 3. Correlation Matrix con't.

$\begin{array}{lllll}11 & 12 & 13 & 14 & 15\end{array}$

\section{1. $\mathrm{AAMR}^{1}$}

2. Social Capital Index

3. Religious Homogeneity

4. Residential Stability

5. \% Male

6. Median Age

7. \% African American

8. $\%$ First Nations ${ }^{2}$

9. \% Hispanic

10. \% Divorced

11. \% with College Degree

12. $\%<1.5 \mathrm{x}$ Federal Poverty Level $\quad-0.60^{* * *}$

13. \% Veteran $0.11^{* * *}-0.21 * * *$

14. \% Farmer as Occupation $\quad-0.32 * * * \quad 0.12 * * * \quad 0.12 * * *$

15. \# of Firearm Suicides

$\begin{array}{lll}-0.33^{* * *} & 0.30^{* * *} \quad 0.07 * * * \quad 0.18^{* * *}\end{array}$

16. \% Evangelical Protestant

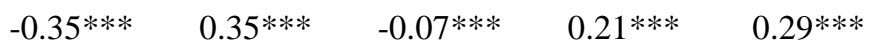

17. \% Catholic

$\begin{array}{lllll}0.37^{* * *} & -0.39^{* * *} & 0.03 & 0.02 & -0.31^{* * *}\end{array}$

18. \# of Deaths from Substance Abuse (alcohol, opioid)

$0.38 * * * \quad-0.15 * * * \quad-0.06 * * \quad-0.67 * * * \quad-0.26 * * *$

19. Rural Flag

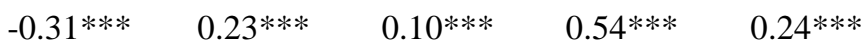

20. Division: Mountain Flag

$\begin{array}{lllll}0.11^{* * *} & -0.03 & 0.12^{* * *} & 0.07 * * * & 0.02\end{array}$

Note: Spearman's rho rank correlation

${ }^{1}$ Age-adjusted to US Census Bureau 2010 population figures.

${ }^{2}$ Dichotomized at the 75 th percentile due to high kurtosis.

$* \mathrm{p}<.05, * * \mathrm{p}<.01, * * * \mathrm{p}<.001$ 
Table 3. Correlation Matrix con’t.

$\begin{array}{llll}16 & 17 & 18 & 19\end{array}$

1. $\mathrm{AAMR}^{1}$

2. Social Capital Index

3. Religious Homogeneity

4. Residential Stability

5. \% Male

6. Median Age

7. \% African American

8. $\%$ First Nations ${ }^{2}$

9. \% Hispanic

10. $\%$ Divorced

11. \% with College Degree

12. $\%<1.5 x$ Federal Poverty Level

13. \% Veteran

14. \% Farmer as Occupation

15. \# of Firearm Suicides

16. \% Evangelical Protestant

17. $\%$ Catholic

$-0.44 * * *$

18. \# of Deaths from Substance

Abuse (alcohol, opioid)

$-0.16 * * * \quad 0.20 * * *$

19. Rural Flag

$0.12 * * *-0.09 * * *-0.56 * * *$

20. Division: Mountain Flag

$\begin{array}{llll}-0.27 * * * & 0.09 * * * & -0.02 & 0.06 * * *\end{array}$

Note: Spearman's rho rank correlation

${ }^{1}$ Age-adjusted to US Census Bureau 2010 population figures.

${ }^{2}$ Dichotomized at the 75 th percentile due to high kurtosis.

$* \mathrm{p}<.05, * * \mathrm{p}<.01, * * * \mathrm{p}<.001$ 
Finally, residential stability is negatively associated with rural counties, but is positively correlated with the counties of the Mountain Division.

Table 4 presents the results of a negative binomial regression of the measure of residential stability on age-adjusted suicide rates with controls adjusted for. Residential stability, the variable this analysis uses to test Demographic conceptualizations of social integration, fails as a significant predictor of age-adjusted county-level suicide rates when measured alone, against the counties of the Mountain Division, and net controls. By itself (Model 1) and along with the counties of the Mountain Division (Model 2), the aggregate measure displays not only a lack of statistical significance but seemingly exacerbates suicide rates within the model. The addition of the suite of demographic controls in Model 3 does correct the sign of the coefficient but the measure continues to demonstrate inadequate improbability to allow us to reject the null hypothesis. Model 4 adds controls capturing the effect of the social environment - the aggregate of the characteristics of individuals occupying the social space. It is here that this measure of the Demographic model best performs, but this brief foray into explanatory power ends with the addition of measures capturing stress and trauma in Model 5.

Table 5 presents the results of a negative binomial regression of the measure of religious homogeneity against age-adjusted suicide rates and controls. Religious Homogeneity is the central concept behind compositional conceptualizations of social integration. Model 6 demonstrates that as the level of religious homogeneity rises within a county, it is significantly associated with a drop in suicide rate, a relationship that holds when the counties of the Mountain Division are added in Model 7. 
Table 4. Coefficients of Negative Binomial Regression of County-level Age-adjusted Suicide Rates on Demographic and Control Variables.

\begin{tabular}{|c|c|c|c|c|c|}
\hline & 1 & 2 & 3 & 4 & 5 \\
\hline Constant & $2.674 * * *$ & $2.638 * * *$ & $3.060 * * *$ & $2.475 * * *$ & $1.716^{* * *}$ \\
\hline Residential Stability & 0.013 & 0.007 & -0.005 & $-0.022 *$ & 0.003 \\
\hline Division: Mountain Flag & & $0.343 * * *$ & $0.320 * * *$ & $0.344 * * *$ & $0.280 * * *$ \\
\hline$\%$ Male & & & $-0.970 *$ & -0.719 & -0.566 \\
\hline Median Age & & & 0.005 & $0.011 * * *$ & -0.002 \\
\hline$\%$ African American & & & $-0.517 * * *$ & $-0.783 * * *$ & $-0.872 * * *$ \\
\hline$\%$ First Nations ${ }^{1}$ & & & $-0.067 *$ & $-0.071 *$ & -0.005 \\
\hline$\%$ Hispanic & & & $-0.375 * * *$ & $-0.276^{*}$ & $-0.431 * * *$ \\
\hline$\%$ with College Degree & & & & -0.345 & 0.529 \\
\hline $\begin{array}{l}\% \text { Farmer as } \\
\text { Occupation }\end{array}$ & & & & $-3.704 * * *$ & -1.617 \\
\hline \# of Firearm Suicides & & & & $0.568 * * *$ & $0.562 * * *$ \\
\hline$\%$ Catholic & & & & -0.073 & 0.155 \\
\hline $\begin{array}{l}\% \text { Evangelical } \\
\text { Protestant }\end{array}$ & & & & 0.119 & 0.088 \\
\hline Rural Flag & & & & $-0.120 * * *$ & $-0.112 * *$ \\
\hline$\%$ Divorced & & & & & $3.092 * * *$ \\
\hline $\begin{array}{l}\%<1.5 x \text { Federal } \\
\text { Poverty Level }\end{array}$ & & & & & $1.037 * *$ \\
\hline$\%$ Veteran & & & & & $3.239 * * *$ \\
\hline $\begin{array}{l}\text { \# of Deaths from } \\
\text { Substance Abuse } \\
\text { (alcohol, opioid) }\end{array}$ & & & & & $0.001 * *$ \\
\hline$N$ & 3,146 & 3,146 & 3,146 & 3,146 & 3,146 \\
\hline Log Likelihood & $-11,664$ & $-11,653$ & $-11,643$ & $-11,619$ & $-11,604$ \\
\hline AIC & 23,334 & 23,313 & 23,303 & 23,267 & 23,244 \\
\hline
\end{tabular}

Note: Unstandardized coefficients.

${ }^{1}$ Dichotomized at the 75 th percentile due to high kurtosis.

${ }^{*} \mathrm{p}<.05 ;{ }^{* *} \mathrm{p}<.01 ;{ }^{* * *} \mathrm{p}<.001$ 
Table 5. Coefficients of Negative Binomial Regression of County-level Age-adjusted Suicide Rates on Compositional and Control Variables.

\begin{tabular}{|c|c|c|c|c|c|}
\hline & 6 & 7 & 8 & 9 & 10 \\
\hline Constant & $2.716 * * *$ & $2.679 * * *$ & $3.164 * * *$ & $2.532 * * *$ & $1.781 * * *$ \\
\hline Religious Homogeneity & $-0.251 * *$ & $-0.249 * *$ & $-0.278 * *$ & $-0.433 * *$ & -0.190 \\
\hline Division: Mountain Flag & & $0.344 * * *$ & $0.316^{* * * *}$ & $0.360 * * *$ & $0.295 * * *$ \\
\hline$\%$ Male & & & $-1.126^{*}$ & -0.729 & -0.648 \\
\hline Median Age & & & 0.005 & $0.009^{* *}$ & -0.001 \\
\hline$\%$ African American & & & $-0.519 * * *$ & $-0.776 * * *$ & $-0.880 * * *$ \\
\hline$\%$ First Nations ${ }^{1}$ & & & $-0.068 *$ & $-0.075^{*}$ & -0.006 \\
\hline$\%$ Hispanic & & & $-0.343 * *$ & $-0.310^{*}$ & $-0.444 * * *$ \\
\hline$\%$ with College Degree & & & & -0.306 & 0.501 \\
\hline$\%$ Farmer as Occupation & & & & $-2.971 * * *$ & $-1.470^{*}$ \\
\hline \# of Firearm Suicides & & & & $0.559 * * *$ & $0.562 * * *$ \\
\hline$\%$ Catholic & & & & 0.121 & 0.232 \\
\hline$\%$ Evangelical Protestant & & & & $0.394 * *$ & 0.203 \\
\hline Rural Flag & & & & $-0.102 * *$ & $-0.107 * *$ \\
\hline$\%$ Divorced & & & & & $2.925 * * *$ \\
\hline$\%<1.5 x$ Federal Poverty Level & & & & & $1.008 * * *$ \\
\hline$\%$ Veteran & & & & & $3.165^{* * *}$ \\
\hline $\begin{array}{l}\text { \# of Deaths from Substance } \\
\text { Abuse (alcohol, opioid) }\end{array}$ & & & & & $0.001 * *$ \\
\hline$N$ & 3,146 & 3,146 & 3,146 & 3,146 & 3,146 \\
\hline Log Likelihood & $-11,664$ & $-11,652$ & $-11,642$ & $-11,618$ & $-11,604$ \\
\hline AIC & 23,332 & 23,311 & 23,299 & 23,265 & 23,243 \\
\hline
\end{tabular}

Note: Unstandardized coefficients...

${ }^{1}$ Dichotomized at the 75 th percentile due to high kurtosis.

${ }^{*} \mathrm{p}<.05 ;{ }^{* *} \mathrm{p}<.01 ;{ }^{* * *} \mathrm{p}<.001$ 
Adding demographic controls in Model 8 adds to the protective effect demonstrated by the measure of religious homogeneity, as does the addition of characteristics of the social environment in Model 9. The measures capturing life stressors and personal traumas finally rob religion of its explanatory power in Model 10.

Table 6 presents the results of a negative binomial regression of the measure of social capital against age-adjusted suicide rates and controls. Social capital demonstrates statistically significant protection against suicide in all five models: alone (Model 11), against the outcome variable and the counties of the Mountain Division (Model 12), and net of demographic controls (Model 13). The addition of characteristics of the social environment (Model 14) and life stressors and traumas (Model 15) somewhat lessen the effect overall, but do not diminish its explanatory power.

Finally, Table 7 presents the results of a negative binomial regression of all three conceptual models against age-adjusted suicide rates and controls. When regressed against the outcome variable and fellow predictors (Model 16), as well as against those and the counties of the Mountain Division (Model 17), residential stability demonstrates nothing suggesting the relationship between the aggregate measure and age-adjusted suicide mortality to be anything other than chance. Religious homogeneity, the measure representing the compositional theoretical construct, does show explanatory promise across these limited models, but loses it net of the entire suite of controls (Model 20). Only the ecological measure, that of social capital, demonstrates a consistent ability to effect county-level suicide rates. 
Table 6. Coefficients of Negative Binomial Regression of County-level Age-adjusted Suicide Rates on Ecological and Control Variables.

\begin{tabular}{|c|c|c|c|c|c|}
\hline & 11 & 12 & 13 & 14 & 15 \\
\hline Constant & $2.673 * * *$ & $2.636 * * *$ & $2.845 * * *$ & $2.341 * * *$ & $1.697 * * *$ \\
\hline Social Capital & $-0.034 * * *$ & $-0.039 * * *$ & $-0.084 * * *$ & $-0.053 * * *$ & $-0.037 * *$ \\
\hline Division: Mountain Flag & & $0.356 * * *$ & $0.343 * * *$ & $0.332 * * *$ & $0.280 * * *$ \\
\hline$\%$ Male & & & $-1.233^{*}$ & -0.775 & -0.758 \\
\hline Median Age & & & $0.014 * * *$ & $0.013 * * *$ & 0.001 \\
\hline$\%$ African American & & & $-0.557 * * *$ & $-0.748 * * *$ & $-0.856 * * *$ \\
\hline$\%$ First Nations ${ }^{1}$ & & & $-0.073 *$ & $-0.078^{*}$ & -0.009 \\
\hline$\%$ Hispanic & & & $-0.482 * * *$ & $-0.370 * *$ & $-0.487 * * *$ \\
\hline$\%$ with College Degree & & & & 0.105 & $0.789 *$ \\
\hline$\%$ Farmer as Occupation & & & & $-2.267 * *$ & -0.841 \\
\hline \# of Firearm Suicides & & & & $0.567 * * *$ & $0.564 * * *$ \\
\hline$\%$ Catholic & & & & -0.026 & 0.183 \\
\hline$\%$ Evangelical Protestant & & & & 0.120 & 0.082 \\
\hline Rural Flag & & & & $-0.093 * *$ & $-0.097 * *$ \\
\hline$\%$ Divorced & & & & & $2.899 * * *$ \\
\hline$\%<1.5 x$ Federal Poverty Level & & & & & $0.989 * *$ \\
\hline$\%$ Veteran & & & & & $3.254 * * *$ \\
\hline $\begin{array}{l}\text { \# of Deaths from Substance Abuse } \\
\text { (alcohol, opioid) }\end{array}$ & & & & & $0.001 * *$ \\
\hline$N$ & 3,146 & 3,146 & 3,146 & 3,146 & 3,146 \\
\hline Log Likelihood & $-11,663$ & $-11,651$ & $-11,633$ & $-11,618$ & $-11,603$ \\
\hline AIC & 23,330 & 23,308 & 23,282 & 23,263 & 23,241 \\
\hline
\end{tabular}

Note: Unstandardized coefficients...

${ }^{1}$ Dichotomized at the 75 th percentile due to high kurtosis.

${ }^{*} \mathrm{p}<.05 ;{ }^{* *} \mathrm{p}<.01 ;{ }^{* * *} \mathrm{p}<.001$ 
Table 7. Coefficients of Negative Binomial Regression of County-level Age-adjusted Suicide Rates on Predictor and Control Variables.

\begin{tabular}{|c|c|c|c|c|c|}
\hline & 16 & 17 & 18 & 19 & 20 \\
\hline Constant & $2.706 * * *$ & $2.667 * * *$ & $2.958 * * *$ & $2.445 * * *$ & $1.777 * * *$ \\
\hline Residential Stability & 0.007 & 0.001 & $-0.028^{*}$ & $-0.033 * *$ & -0.007 \\
\hline Religious Homogeneity & $-0.199 *$ & $-0.188^{*}$ & $-0.195^{*}$ & $-0.414 * *$ & -0.181 \\
\hline Social Capital & $-0.029 * *$ & $-0.035^{* * *}$ & $-0.087 * * *$ & $-0.059 * * *$ & $-0.039 * *$ \\
\hline Division: Mountain Flag & & $0.353 * * *$ & $0.352 * * *$ & $0.366 * * *$ & $0.296^{* * *}$ \\
\hline$\%$ Male & & & $-1.567 * * *$ & $-1.165^{* * *}$ & -0.879 \\
\hline Median Age & & & $0.016^{* * *}$ & $0.015 * * *$ & 0.001 \\
\hline$\%$ African American & & & $-0.606^{* * *}$ & $-0.795 * * *$ & $-0.863 * * *$ \\
\hline$\%$ First Nations ${ }^{1}$ & & & $-0.066^{*}$ & $-0.071 *$ & -0.009 \\
\hline$\%$ Hispanic & & & $-0.470 * * *$ & $-0.425^{* * *}$ & $-0.499 * *$ \\
\hline$\%$ with College Degree & & & & 0.120 & $0.751^{*}$ \\
\hline $\begin{array}{l}\% \text { Farmer as } \\
\text { Occupation }\end{array}$ & & & & $-1.869^{*}$ & -0.725 \\
\hline \# of Firearm Suicides & & & & $0.579 * * *$ & $0.567 * * *$ \\
\hline$\%$ Catholic & & & & 0.177 & 0.255 \\
\hline $\begin{array}{l}\% \text { Evangelical } \\
\text { Protestant }\end{array}$ & & & & $0.346^{* *}$ & 0.189 \\
\hline Rural Flag & & & & $-0.088 * *$ & $-0.093 * *$ \\
\hline$\%$ Divorced & & & & & $2.695^{* * *} *$ \\
\hline $\begin{array}{l}\%<1.5 x \text { Federal } \\
\text { Poverty Level }\end{array}$ & & & & & $0.938 * * *$ \\
\hline$\%$ Veteran & & & & & $3.178 * * *$ \\
\hline $\begin{array}{l}\text { \# of Deaths from } \\
\text { Substance Abuse } \\
\text { (alcohol, opioid) }\end{array}$ & & & & & $0.001 *$ \\
\hline$N$ & 3,146 & 3,146 & 3,146 & 3,146 & 3,146 \\
\hline Log Likelihood & $-11,662$ & $-11,650$ & $-11,631$ & $-11,615$ & $-11,602$ \\
\hline AIC & 23,332 & 23,310 & 23,283 & 23,261 & 23,245 \\
\hline
\end{tabular}

Note: Unstandardized coefficients...

${ }^{1}$ Dichotomized at the 75 th percentile due to high kurtosis.

${ }^{*} \mathrm{p}<.05 ;{ }^{* *} \mathrm{p}<.01 ;{ }^{* * *} \mathrm{p}<.001$ 
Across all models, as with the correlations, we are also presented with expected and unexpected results with regard to the controls. Of the demographic controls, only percent First Nations and Median Age demonstrated a limited to nonexistent association with the outcome variable net predictors. Quite unexpectedly, however, proportion male consistently showed a protective effect with regard to suicide rates, an effect that remained robust net all other controls and predictors, and one that is manifestly contrary to expectations generated by a review of the literature. The measures capturing characteristics of the social environment showed much higher levels of variation, with the exception of the number of firearm suicides and the overall rurality of the individual county, both of which remained highly predictive throughout, though rurality, like proportion male, showed an unexpected protective aspect. The controls quantifying stressors and personal trauma showed the most impact. The addition of these controls, of which percent divorced and percent veteran proved the most influential, served to eliminate the explanatory ability of the Demographic and Compositional framings in almost every model. Only the Ecological measure, social capital, remained robustly explicative throughout.

Overall, these models present us with an interesting combination of expected and unexpected results. Social capital presents a potent candidate for capturing the protective aspects of social networks, supporting Hypothesis 2, but neither religious homogeneity nor residential stability demonstrated a significant relationship with the outcome variable net controls, rejecting Hypotheses 1 and 3. Unlike residential stability, religious homogeneity does demonstrate a predictive and protective relationship with regard to the outcome variable, but this relationship vanishes in the final models. Furthermore, the regression 
demonstrates unexpected relationships between the outcome, predictor, and control variables. Two of the sociodemographic and environmental covariates behave in ways contrary to that predicted in the literature. In all models, proportion male exerts a protective effect with regard to suicide and rurality seems to exert a protective effect across all models, findings that directly contradict that of the literature. 
Discussion

The goal of this analysis was to comparatively evaluate three competing frameworks of social integration with regard to their ability to help us to understand the geographic variation in suicide rates in the United States. The compositional, or 'Durkheimian', framework posits that, with regard to understanding suicide, religion is paramount. As the social institution most directly concerned with pronouncing sanction on suicide, proponents argue, religious adherence and denominational variation therein offer us a window into the spread and level of social prohibition against suicide, as well as providing a convenient proxy for approximating a 'social safety net' of connectedness. The ecological framework builds on the compositional by expanding the scope of social institutions under consideration beyond just factors describing characteristics of individuals to those describing interactions between individuals - such measures as political and census participation, labor organization prevalence, and, of course, number of bowling alleys. The ecological understanding attempts to holistically capture the entire web of social interconnectedness within a community through the construction of a composite aggregated from a number of proxies for interaction. Finally, the demographic framework attempts to circumvent the approximate nature of both the traditionalist and civic frames by looking to the stability of populations themselves. If large numbers of people are moving through communities, this view theorizes, there exists less opportunity for the creation of stable social networks - the backbone of social interconnectedness.

In order to examine the utility of these frameworks, this analysis subjected each of them to three tests. First, each frame was evaluated directly against county-level suicide 
rates. The county represents the smallest, or most macroscopically granular, level at which US suicide rates may be reliably evaluated and provides several attractive qualities over the use of SMSAs, common in the literature. Counties allow for granular discussion of rurality and suicide, poverty and suicide, a whole host of characteristics of individuals that become amorphous with regard to effect at higher levels of analysis. A pool of such characteristics was assessed and representative qualities for each characteristic chosen to form this analysis' controls. The three frames were then evaluated with regard to explanatory power net these characteristics. Lastly, the US region that demonstrates the most elevated suicide rate was selected and the three frames evaluated with regard to their ability to account for this phenomenon.

At each level of analysis, the civic, or ecological, frame proved the most useful and consistent of the three in understanding the nature of the relationship between the social realm and suicide. This result supports the $3 \mathrm{ST}$ model of suicide by lending credence to the idea that a characteristic of a group, not an individual, is instrumental in explaining the variance in suicide rates. While the overall effect found in this analysis may be small, certainly over-shadowed by the effect of characteristics of individuals such as sex, marital status, economic status, and veteran status, from a population perspective the effects may be far reaching. The range of social capital captured by Penn State's Northeast Regional Center for Rural Development, the measure used here, stretches from -3.925 at its lowest to 17.441 at its highest, with a standard deviation of 1.34 . This indicates that a seemingly minor change in overall social capital, a raise of one standard deviation in all counties nation-wide, would result in 1,524 fewer suicides nationally. The holistic nature of the civic 
viewpoint - examining many facets of social interconnectedness, not one - seems to give this frame the flexibility necessary to deal with a wide variety of social groups and positions. This finding supports other work that has demonstrated the falling impact of religion as the primary vehicle for social cohesion (Pescosolido and Georgianna 1989; van Tubergen et al. 2005).

This analysis also generated some findings that, while unrelated to the central purpose pursued here, deserve some consideration. While most of the control variables performed as expected, two did not and their refusal to conform raises several interesting questions. Two of the central tenets of the suicide literature are that males commit suicide at rates much higher than females (Denney et al. 2009; Ivey-Stephenson et al. 2017; Stone et al. 2018) and that rural populations commit suicide at rates much higher than their urban counterparts (Faupel et al. 1987; Ivey-Stephenson et al. 2017; Kegler, Stone, and Holland 2017). Yet, this analysis found that proportion of males within a county and that county's level of rurality, both aggregative proxies commonly used to capture these trends, provided a protective effect against suicide as they increased. Figure 3 demonstrates the relationship between age-adjusted suicide rate and proportion of the county population that is male. In it we see that the relationship between these two factors is polynomial - rising precisely at the level of proportionality found in most urban centers, those areas most commonly captured by analyses relying on SMSAs. As the proportionality increases past the 55\% level, however, it begins to fall and continues falling through $70 \%$. One possible answer may be that this trend has always existed in the data, but has been masked by the effect of larger, proportional urban populations. Another, more intriguing possibility is that we are 
seeing the effects of a new kind of social integration taking form. The precise mechanism at work here is opaque and is far beyond the scope of the present analysis, but it is clear that further study is necessary with regard to these assumptions that underlie so much of the sociological work on suicide. 
Conclusion

Areal variations in suicide rate have long troubled thanatological scholars. This analysis has tried to assist in the effort to understand these variations by evaluating the three primary conceptualizations of social integration, thought to be the fundamental mediating factor between ideation and action, proposed by the literature. Demographic (residential stability), compositional (religious homogeneity), and ecological (social capital) formulations of the nature of social integration were each tested against countylevel age-adjusted suicide rate in order to understand their overall protective aspect. They were then tested against the counties of the Mountain Division, specifically, in order to determine their usefulness in explaining the heretofore opaque rates of suicide in that region of the United States. Finally, they were each evaluated with regard to their explanatory power in understanding suicide rates net controls. The ecological conception of social integration proved the most predictive and associative of the three.

This analysis was subject to certain limitations, of course. Privacy considerations meant that analysis had to take place at the county level, which, while superior to the metropolitan exclusivity of SMSA analysis, does little to address concerns of falling prey to the ecological fallacy. Limited individual-level data made definitive causal explanation impossible, therefore this analysis tries to point to associations and not offer definitive claims.

Further research should examine areal variation in suicide rate with an understanding of the complex and changing nature of social integration. As religious connection loses potency as a socially binding force, it makes sense for scholars to expand 
their conceptualization of the ties between individuals to encompass other, non-secular institutions. While this analysis cannot definitely say that changing population demographics are not associated with suicide rates, these results suggest that, at the very least, population shifts may be rather glacial in their effect - predictive at scales beyond the time frame considered here. Certainly, the results found suggest there to be merit in the notion that place, not simply the characteristics of individuals, is influential in the process of suicide. 
References

Agerbo, Esben, Jonathan A. C. Sterne, and David J. Gunnell. 2007. “Combining Individual and Ecological Data to Determine Compositional and Contextual Socio-Economic Risk Factors for Suicide.” Social Science \& Medicine 64(2):451-61.

American Foundation for Suicide Prevention. 2016. "Suicide Statistics." AFSP. Retrieved April 21, 2019 (https://afsp.org/about-suicide/suicide-statistics/).

Bacon, Rachel, Roger Finke, and Dale Jones. 2018. "Merging the Religious Congregations and Membership Studies: A Data File for Documenting American Religious Change." Review of Religious Research 60(3):403-22.

Bainbridge, William Sims. 1989. "The Religious Ecology of Deviance." American Sociological Review 54(2):288-95.

Baller, Robert D. and Kelly K. Richardson. 2002. "Social Integration, Imitation, and the Geographic Patterning of Suicide." American Sociological Review 67(6):873-88.

Barkan, Steven E., Michael Rocque, and Jason Houle. 2013. "State and Regional Suicide Rates: A New Look at an Old Puzzle.” Sociological Perspectives 56(2):287-97.

Barranco, Raymond E. 2016. "Suicide, Religion, and Latinos: A Macrolevel Study of U.S. Latino Suicide Rates.” The Sociological Quarterly 57(2):256-81.

Breault, K. D. 1986. "Suicide in America: A Test of Durkheim's Theory of Religious and Family Integration, 1933-1980.” American Journal of Sociology 92(3):628-656.

Bullman, Tim, Aaron Schneiderman, and Robert Bossarte. 2018. "Suicide Risk by Unit Component among Veterans Who Served in Iraq or Afghanistan." Archives of Suicide Research 22(1):1-10.

Burr, Jeffrey A., John T. Hartman, and Donald W. Matteson. 1999. "Black Suicide in U.S. Metropolitan Areas: An Examination of the Racial Inequality and Social Integration-Regulation Hypotheses." Social Forces 77(3):1049.

Burr, Jeffrey, Patricia Mccall, and Eve Powell-Griner. 1994. "Catholic Religion and Suicide: The Mediating Effect of Divorce.” Social Science Quarterly 75(2).

Centers for Disease Control and Prevention. 1997. "Regional Variations in Suicide RatesUnited States, 1990-1994." MMWR. Morbidity and Mortality Weekly Report 46(34).

Curtin, Sally C., M. Warner, and H. Hedegaard. 2016. Increase in Suicide in the United States, 1999-2014. Hyattsville, MD: U.S. Department of Health and Human 
Services, Centers for Disease Control and Prevention, National Center for Health Statistics.

Cutchin, Malcolm P. and Robert R. Churchill. 1999. "Scale, Context, and Causes of Suicide in the United States." Social Science Quarterly (University of Texas Press) 80(1):97-114.

Denney, Justin T., Richard G. Rogers, Patrick M. Krueger, and Tim Wadsworth. 2009. "Adult Suicide Mortality in the United States: Marital Status, Family Size, Socioeconomic Status, and Differences by Sex." Social Science Quarterly 90(5):1167-85.

Department of Veterans Affairs, Veterans Health Administration, Office of Suicide Prevention. 2018. VA National Suicide Data Report 2005-2015.

Durkheim, Émile and George Simpson. 1999. Suicide: A Study in Sociology. New York: Free Press.

Ellison, Christopher G., Jeffrey A. Burr, and Patricia L. McCall. 1997. "Religious Homogeneity and Metropolitan Suicide Rates." Social Forces 76(1):273-99.

Faupel, Charles E., Gregory S. Kowalski, and Paul D. Starr. 1987. "Sociology's One Law: Religion and Suicide in the Urban Context." Journal for the Scientific Study of Religion 26(4):523-34.

Harper, Sam, S. Yang, and J. Lynch. 2008."Is There a Suicide Belt in the United States?" Presented at the 41st Annual Meeting of the Society for Epidemiologic Research, June 1.

Heron, Melonie. 2018. "Deaths: Leading Causes for 2016." National Vital Statistics Reports 67(6):77.

Hsieh, Ning. 2017. “A Global Perspective on Religious Participation and Suicide.” Journal of Health and Social Behavior 58(3):322-39.

Ivey-Stephenson, Asha Z., Alex E. Crosby, Shane P. D. Jack, Tadesse Haileyesus, and Marcie-jo Kresnow-Sedacca. 2017. "Suicide Trends Among and Within Urbanization Levels by Sex, Race/Ethnicity, Age Group, and Mechanism of Death — United States, 2001-2015.” MMWR. Surveillance Summaries 66(18):1-16.

Joiner, Thomas E. 2005. Why People Die by Suicide. Cambridge, Mass: Harvard University Press.

Kawachi, Ichiro. 1997. "Long Live Community: Social Capital as Public Health." American Prospect 56-59. 
Kawachi, Ichiro, Bruce P. Kennedy, Kimberly Lochner, and Deborah Prothrow-Stith. 1997. "Social Capital, Income Inequality, and Mortality." The American Journal of Public Health 87(9).

Kegler, Scott R., Deborah M. Stone, and Kristin M. Holland. 2017. "Trends in Suicide by Level of Urbanization - United States, 1999-2015." MMWR. Morbidity and Mortality Weekly Report 66(10):270-73.

Klonsky, E. David and Alexis M. May. 2015. "The Three-Step Theory (3ST): A New Theory of Suicide Rooted in the 'Ideation-to-Action' Framework." International Journal Of Cognitive Therapy 8(2):114-29.

Kowalski, Gregory S., Charles E. Faupel, and Paul D. Starr. 1987. "Urbanism and Suicide: A Study of American Counties." Social Forces 66(1):85-101.

Kushner, Howard I. and Claire E. Sterk. 2005. "The Limits of Social Capital: Durkheim, Suicide, and Social Cohesion." American Journal of Public Health 95(7):1139-43.

Lester, David. 1995. "Explaining the Regional Variation of Suicide and Homicide." Archives of Suicide Research 1(3):159-74.

Lester, David. 1996. "The Regional Variation of Suicide in the United States in 1880 and 1980.” OMEGA - Journal of Death and Dying 34(1):81-84.

McMurray, Coleen. 2004. "Nearly Half of Teens Aware of Peer Suicide Attempts." Gallup.Com. Retrieved April 2019 (https://news.gallup.com/poll/11776/Nearly-Half-Teens-Aware-Peer-SuicideAttempts.aspx).

National Center for Health Statistics. 2019. Multiple Cause of Death (1999-2010), as Compiled from Data Provided by the 57 Vital Statistics Jurisdictions through the Vital Statistics Cooperative Program. Atlanta, Georgia: Centers for Disease Control.

O'Connor, Rory C. 2011. “The Integrated Motivational-Volitional Model of Suicidal Behavior." Crisis 32(6):295-98.

Office of Minority Health and Health Equity. 2018. "Leading Causes of Death White Males, US - 2015." Centers for Disease Control and Prevention. Retrieved April 21, 2019 (https://www.cdc.gov/healthequity/lcod/men/2015/white/index.htm).

van Orden, Kimberly A., Tracy K. Witte, Kelly C. Cukrowicz, Scott R. Braithwaite, Edward A. Selby, and Jr. Joiner, Thomas E. 2010. "The Interpersonal Theory of Suicide." Psychological Review 117(2):575-600. 
Pepper, Carolyn M. 2017. "Suicide in the Mountain West Region of the United States." Crisis 38(5):344-50.

Pescosolido, Bernice A. 1990. "The Social Context of Religious Integration and Suicide: Pursuing the Network Explanation.” The Sociological Quarterly 31(3):337-57.

Pescosolido, Bernice A. and Sharon Georgianna. 1989. "Durkheim, Suicide, and Religion: Toward a Network Theory of Suicide." American Sociological Review 54(1).

Pescosolido, Bernice A. and Robert Mendelsohn. 1986. "Social Causation or Social Construction of Suicide? An Investigation into the Social Organization of Official Rates." American Sociological Review 51(1):80.

Putnam, Robert D. 2000. Bowling Alone: The Collapse and Revival of American Community. New York: Simon \& Schuster.

Ringgenberg, Wendy, Corinne Peek-Asa, Kelley Donham, and Marizen Ramirez. 2018. "Trends and Characteristics of Occupational Suicide and Homicide in Farmers and Agriculture Workers, 1992-2010: Suicide and Homicide in Farmers and Ag Workers." The Journal of Rural Health 34(3):246-53.

Rupasingha, Anil, Stephan J. Goetz, and David Freshwater. 2006. "The Production of Social Capital in US Counties." The Journal of Socio-Economics 35(1):83-101.

Shepard, Donald S., Deborah Gurewich, Aung K. Lwin, Gerald A. Reed, and Morton M. Silverman. 2016. "Suicide and Suicidal Attempts in the United States: Costs and Policy Implications." Suicide and Life-Threatening Behavior 46(3):352-62.

Smith, Nathan Daniel Lucia and Ichiro Kawachi. 2014. "State-Level Social Capital and Suicide Mortality in the 50 U.S. States." Social Science \& Medicine 120(Supplement C):269-77.

Stack, Steven. 2000a. "Suicide: A 15-Year Review of the Sociological Literature Part I: Cultural and Economic Factors." Suicide and Life-Threatening Behavior 30(2):145-162.

Stack, Steven. 2000b. "Suicide: A 15-Year Review of the Sociological Literature Part II: Modernization and Social Integration Perspectives." Suicide and Life-Threatening Behavior 30(2):163-176.

Stark, Rodney, Daniel P. Doyle, and Jesse Lynn Rushing. 1983. "Beyond Durkheim: Religion and Suicide." Journal for the Scientific Study of Religion 22(2):120-31.

Stone, Deborah M., Thomas R. Simon, Katherine A. Fowler, Scott R. Kegler, Keming Yuan, Kristin M. Holland, Asha Z. Ivey-Stephenson, and Alex E. Crosby. 2018. "Vital Signs: Trends in State Suicide Rates — United States, 1999-2016 and 
Circumstances Contributing to Suicide - 27 States, 2015." MMWR. Morbidity and Mortality Weekly Report 67(22):617-24.

Tippett, Rebecca. 2014. "Mortality and Cause of Death, 1900 v. 2010." Carolina $\begin{array}{llll}\text { Demography. } & \text { Retrieved } & \text { April } & 219\end{array}$ (https://demography.cpc.unc.edu/2014/06/16/mortality-and-cause-of-death-1900v-2010/).

van Tubergen, Frank, Manfred te Grotenhuis, and Wout Ultee. 2005. "Denomination, Religious Context, and Suicide: Neo-Durkheimian Multilevel Explanations Tested with Individual and Contextual Data.” American Journal of Sociology 111(3):797823.

Turner, Bryan. 2003. "Social Capital, Inequality and Health: The Durkheimian Revival." Social Theory \& Health 1(1):4-20.

Wadsworth, Tim and Charis E. Kubrin. 2007. "Hispanic Suicide in U.S. Metropolitan Areas: Examining the Effects of Immigration, Assimilation, Affluence, and Disadvantage." American Journal of Sociology 112(6):1848-85.

Wray, M., C. Colen, and B. Pescosolido. 2011. "The Sociology of Suicide.” Annual Review Of Sociology, Vol 37 37(1):505-528. 